\title{
A study on clinical profile, management and outcome in pediatric patients admitted with scorpion envenomation
}

\author{
Kiruthika Umapathi $^{1 *}$, P. Boopalan ${ }^{1}$, V. P. Maheshkumar ${ }^{1}$, R. Ramamoorthy ${ }^{2}$
}

${ }^{1}$ Department of Pharmacy, Annamalai University, Chidambaram, Tamilnadu, India

${ }^{2}$ Department of Pediatrics, Raja Muthiah medical college and hospital, Chidambaram, Tamilnadu, India

Received: 31 July 2020

Accepted: 04 September 2020

\section{*Correspondence:}

Dr. Kiruthika Umapathi,

Email: kiruthikaumadevi@gmail.com

Copyright: (C) the author(s), publisher and licensee Medip Academy. This is an open-access article distributed under the terms of the Creative Commons Attribution Non-Commercial License, which permits unrestricted non-commercial use, distribution, and reproduction in any medium, provided the original work is properly cited.

\begin{abstract}
Background: Scorpion envenomation is a common medical emergency. The main aim is to study clinical profile, management and outcome.

Methods: Prospective observational study of Scorpion envenomation cases for six months. case sheets were analysed for clinical profile, symptoms, complications, management and outcome.

Results: During the study period first 50 cases were admitted and treated for the following results $66 \%$ were males and $34 \%$ were females, $46 \%$ were upper extremity and $54 \%$ were lower extremity. common clinical symptoms are pain at site, autonomic storm, palpitation, headaches, abdominal pain, altered sensorium, vomiting. $40 \%$ of patients received prazosin with 1-2 hrs. the major complications were myocarditis, encephalopathy, Peripheral circulatory failure \& congestive cardiac failure. There was no mortality in this study.

Conclusions: The study finding shows that early and effective use of prazosin treatment showed good outcome in patients. Less complications were seen in patients those who received the first aid. This study concludes that majority of patient were exposed to complication due to shortfall in education, awareness and pre-hospitalization. We, as a clinical pharmacist, tried to create awareness and provide education to health care workers in all primary health care center through distributing pamphlets to general public in and around hospital.
\end{abstract}

Keywords: Scorpion, Envenomation, Clinical profile, Peripheral circulatory failure, Myocarditis, Prazosin

\section{INTRODUCTION}

Scorpion envenomation is a common medical emergency. ${ }^{1}$ and its mortality is higher in children's than adults in our country. Every year more than ten lakhs children of scorpion envenomation were reported worldwide. It is referred as the second most common envenomation next to the snake bite. There are more than 1500 species of scorpions are found throughout the world from that only eighty species found in India in that only three species are found to be poisonous and they are Hottentotta tumulus, Heterometrus swammerdami, Heterometrus bengalensis. Scorpion's sting more in pediatric victim due to their smaller body size and It also involves many organ damages in the body simultaneously producing multiple organ dysfunction. In this condition an alpha blocker Prazosin plays a major role. It is a common problem, especially in villages around Chidambaram. The usefulness of prazosin therapy in scorpion sting was scientifically established in mideighties by Bawaskar et al which was later strengthened by many other investigators. ${ }^{2}$ Children are mostly ambulatory and have explorative attitude and hence they have greater chances of envenomation. Mortality is now decreasing with timely intervention and referral. Due to the lack of adequate emergency medical facilities, morbidity and mortality rate of scorpion envenomation is still high in rural areas. ${ }^{3}$ Hence aim is to study the clinical 
profile, management and outcome of the paediatric patients admitted with scorpion envenomation.

\section{METHODS}

\section{Source of data}

Case sheets of children admitted with scorpion envenomation in our hospital.

\section{Study design}

A hospital based prospective observational study. The study protocol was endorsed by the human research ethics committee of the institute prior to the commencement of the study (approval letter no IHEC/0397 Dated 09/01/19)

\section{Study place}

The study was conducted in PICU and WARD in the Department of Paediatrics, Rajah Muthiah Medical College Hospital, Annamalai University, Annamalai Nagar, Chidambaram, Tamil Nadu.

\section{Study period}

The duration of study is from November 2018 to April 2019

\section{Inclusion criteria}

In this study inclusion criteria were patients who were treated as inpatients for diagnosis of scorpion envenomation, patients of both the gender, patients up to 12 years of age.

\section{Exclusion criteria}

In this study exclusion criteria were patients other than scorpion envenomation, patients who were not interested to participate.

\section{Study parameters}

All the case sheets were analysed for the following parameters. It includes age, gender, time of sting, place of sting, site of sting, sting prazosin interval, duration of hospital stay, prazosin dose and signs and symptoms includes pain at the site, autonomic storm, vomiting, palpitation, headaches, abdominal pain, altered sensorium, loss of consciousness and vitals such as heart rate, respiratory rate, blood pressure were recorded and treatment details includes IV fluids ,prazosin, tetanus toxoid, diclofenac, pheniramine maleate, lignocaine, dopamine, paracetamol, dobutamine treatment and ventilatory care were analysed. Outcomes were also analysed. Data analysis was performed using Microsoft office excel software.

\section{RESULTS}

Scorpion sting envenomation is relatively common, sometimes life threatening, time limiting medical emergency in hospitals. It is the common accident encountered in rural parts. Many cases are unreported and true incidence is not known. During the period of study November 2018 to April 2019. 50 children $(n=50)$ were admitted in PICU and ward in Rajah Muthiah Medical Hospital, Chidambaram. Following were observations. In this study maximum number of cases were in the age group of 0-3 years and 4-6 years (Table 1).

Table 1: Age wise distribution $(n=50)$.

\begin{tabular}{|lll|}
$\begin{array}{l}\text { Age } \\
\text { (years) }\end{array}$ & Total & $\begin{array}{l}\text { Percentage } \\
(\%)\end{array}$ \\
\hline $\mathbf{0 - 3}$ & 20 & 40 \\
\hline $\mathbf{4 - 6}$ & 16 & 32 \\
\hline $\mathbf{7 - 9}$ & 5 & 10 \\
\hline $\mathbf{1 0 - 1 2}$ & 9 & 18 \\
\hline
\end{tabular}

Table 2: Gender wise distribution $(n=50)$.

\begin{tabular}{|lll|}
\hline Gender & No of patients & $\begin{array}{l}\text { Percentage } \\
(\%)\end{array}$ \\
\hline Male & 33 & 66 \\
\hline Female & 17 & 34 \\
\hline Total & 50 & 100 \\
\hline
\end{tabular}

During this study 50 paediatric patients were enrolled in which majority of patients were males [66\%] than females [34\%] (Table 2).

Table 3: Time of sting $(n=50)$.

\begin{tabular}{|lll|}
\hline Time & No of patients & $\begin{array}{l}\text { Percentage } \\
(\%)\end{array}$ \\
\hline Day & 23 & 46 \\
\hline Night & 27 & 54 \\
\hline Total & 50 & 100 \\
\hline
\end{tabular}

In this study maximum number of stings were during night time [54\%] compared to day time [46\%] (Table 3).

Table 4: Site of sting $(n=50)$.

\begin{tabular}{|lcc|}
\hline Site of sting & No of patients & $\begin{array}{l}\text { Percentage } \\
(\%)\end{array}$ \\
\hline Upper extremity & 23 & 46 \\
\hline Lower extremity & 27 & 54 \\
\hline
\end{tabular}

In this study 27 patients [54\%] had sting over the lower extremity and $23[46 \%]$ patients were the upper extremity (Table 4). 
Table 5: Place of sting.

\begin{tabular}{|llll|}
\hline $\begin{array}{l}\text { Sr: } \\
\text { no }\end{array}$ & Place of sting & $\begin{array}{l}\text { No of } \\
\text { patients }\end{array}$ & Percentage \\
\hline $\mathbf{1}$ & Indoor & 23 & 46 \\
\hline $\mathbf{2}$ & Outdoor & 27 & 54 \\
\hline
\end{tabular}

In this study, majority of sting occurred in outdoor (54\%) compared to that of during indoor (46\%) (Table 5).

Table 6: Sting-prazosin interval $(n=50)$.

\begin{tabular}{|lll|}
\hline $\begin{array}{l}\text { Sting-prazosin } \\
\text { interval (hrs) }\end{array}$ & No of patients & $\begin{array}{l}\text { Percentage } \\
(\%)\end{array}$ \\
\hline $\mathbf{1}$ & 11 & 22 \\
\hline $\mathbf{1 - 2}$ & 20 & 40 \\
\hline $\mathbf{2 - 3}$ & 11 & 22 \\
\hline $\mathbf{3 - 4}$ & 7 & 14 \\
\hline $\mathbf{4}$ & 1 & 2 \\
\hline
\end{tabular}

In this study, $22 \%$ of patients had received the prazosin within 24 hours and $40 \%$ of patients received prazosin within 1-2 hrs, $22 \%$ of patients received prazosin within 2-3 hrs, $14 \%$ of patients received after $3-4 \mathrm{hrs}, 2 \%$ of patients after 4 hrs (Table 6).

Table 7: Presenting symptoms $(n=50)$.

\begin{tabular}{|llll|}
\hline $\begin{array}{l}\text { S. } \\
\text { no }\end{array}$ & Symptoms & $\begin{array}{l}\text { No of } \\
\text { patients }\end{array}$ & $\begin{array}{l}\text { Percentage } \\
(\%)\end{array}$ \\
\hline $\mathbf{1}$ & Pain at site & 40 & 80 \\
\hline $\mathbf{2}$ & Autonomic storm & 24 & 48 \\
\hline $\mathbf{3}$ & Vomiting & 9 & 18 \\
\hline $\mathbf{4}$ & Palpitation & 7 & 14 \\
\hline $\mathbf{5}$ & Incesant cry & 7 & 14 \\
\hline $\mathbf{6}$ & Headache & 3 & 6 \\
\hline $\mathbf{7}$ & Abdominal pain & 3 & 6 \\
\hline $\mathbf{8}$ & Altered sensorium & 2 & 4 \\
\hline $\mathbf{9}$ & $\begin{array}{l}\text { Loss of } \\
\text { consciousness }\end{array}$ & 1 & 2 \\
\hline
\end{tabular}

Pain at the site was present in 40 patients $(80 \%)$ in our study and resolved spontaneously within 12 to $24 \mathrm{hrs}$ without any local complications. The other common symptoms were, Autonomic storm was present in 24 patients $(48 \%)$, headache was present in 3 patients $(6 \%)$,vomiting was present in 9 patients (18\%), abdominal pain was present in 3 patients $(6 \%)$, palpitation was present in 7 patients $(14 \%)$, loss of consciousness 1 patient $(2 \%)$, Altered sensorium was present in 2 patients (4\%), and incessant cry was present in 7 patients (14\%). Priapism was noted in nearly 15 of male children (Table 7).

In this study, complications were found to be Myocarditis and it was present in 6 patients $(12 \%)$, peripheral circulatory failure was present in 9 patients $(18 \%)$, coronary heart failure was present in 1 patient $(2 \%)$, convulsion was present in 2 patients (4\%), Encephalo pathy was present in 1 patient $(2 \%)$ (Table 8$)$.

Table 8: Complications $(n=50)$.

\begin{tabular}{|llll|}
\hline S. no. & Complications & $\begin{array}{l}\text { No of } \\
\text { patients }\end{array}$ & $\begin{array}{l}\text { Percentage } \\
(\%)\end{array}$ \\
\hline $\mathbf{1}$ & $\begin{array}{l}\text { Peripheral } \\
\text { circulatory failure }\end{array}$ & 9 & 18 \\
\hline $\mathbf{2}$ & Myocarditis & 6 & 12 \\
\hline $\mathbf{3}$ & Encephalopathy & 2 & 4 \\
\hline $\mathbf{4}$ & $\begin{array}{l}\text { Congestive cardiac } \\
\text { failure }\end{array}$ & 1 & 2 \\
\hline
\end{tabular}

Table 9: Management of scorpion envenomation treatment history.

\begin{tabular}{|lll|}
\hline $\begin{array}{l}\text { First aid treatment } \\
\text { Medications }\end{array}$ & No of patients & Percentage \\
\hline Dobutamine & 11 & \\
\hline Tetanus toxoid & 15 & 22 \\
\hline Diclofenac & 4 & 30 \\
\hline Prazosin & 10 & 8 \\
\hline Pheniramine maleate & 5 & 20 \\
\hline Lignocaine & 1 & 10 \\
\hline Dopamine & 1 & 2 \\
\hline Paracetamol & 1 & 2 \\
\hline During hospitalisation & 2 \\
\hline Iv fluids & 50 & \\
\hline Prazosin & 50 & 100 \\
\hline Paracetamol & 34 & 100 \\
\hline Dobutamine & 15 & 68 \\
\hline
\end{tabular}

In this study 48 patient received the first aid management such as tetanus toxoid, paracetamol, diclofenac (given for the pain at the sting site), prazosin, dobutamine, pheniramine maleate, lignocaine, dopamine from local clinic, community health centre and primary healthcare centre for first aid, pain management and supportive care.

During hospitalisation all the 50 patients had received the IV fluids and prazosin at an average dose of $0.5 \mathrm{mg}, 34$ patients received the paracetamol and 15 patients received dobutamine (Table 9).

\section{DISCUSSION}

Scorpion sting envenomation is relatively common, sometimes life threatening, time limiting medical emergency in hospitals. It is the common accident encountered in rural parts. Many cases are unreported and true incidence is not known. In scorpion sting study, the main treatment is supportive care, relieve from symptoms, and use of specific scorpion anti-venom. ${ }^{5}$ Minor symptoms were controlled with anti-histamines and analgesics. ${ }^{4}$ The main aim in use of prazosin is to neutralize the conflicting effect of catecholamine discharged from the brain. other study shows that, there 
was no evidence of benefit effect on conventional administration of scorpion anti- venom to stung patient, irrespective of clinical severity. ${ }^{4}$

In this age distribution of the study showed majority of the patients with scorpion envenomation are belonged to 0-3 years age group accounting for about $40 \%$ whereas the least belonged to 7-9 years of age is about $10 \%$. Maximum number of cases noted in 0-3 years and 4-6 years of age as Pol et al reported 2-7 years as the most involved as group. ${ }^{6}$

During this study 50 paediatric patients were enrolled in which majority of patients were males [66\%] than females [34\%]. Present study states that male children were more exposed than the females this result is consistent with many other studies where similar findings were observed. ${ }^{7,8}$ Because of the fact that boys probably go outside more commonly and play in place where scorpions live. ${ }^{9}$

In this study maximum number of stings were during night time [54\%] compared to day time [46\%] whereas Soren et al study says that maximum sting is during the night time this might because scorpion is more active at night. ${ }^{10}$ A27 patients [54\%] had sting over the lower extremity and 23 [46\%] patients were the upper extremity. In majority of children the site of sting was seen in lower limbs, which was similar to Pol et al, Bosnak et al and Farhlyat's observation. ${ }^{8,9,11}$

In this majority of sting occurred in outdoor (54\%) compared to that of during indoor $(46 \%)$. T. Madhavan et al (2018) study say that a greater number of scorpion sting in children where in indoor where as our study shows more children stung in outdoor. we observed the contrary results may because of our child population involving more outdoor activity like playing in agricultural fields.

Pain at the site was present in 40 patients $(80 \%)$ in our study and resolved spontaneously within 12 to $24 \mathrm{hrs}$ without any local complications. The other common symptoms were, Autonomic storm was present in 24 patients (48\%), headache was present in 3 patients $(6 \%)$, vomiting was present in 9 patients $(18 \%)$, abdominal pain was present in 3 patients $(6 \%)$, palpitation was present in 7 patients (14\%), loss of consciousness 1 patient (2\%), Altered sensorium was present in 2 patients $(4 \%)$,and incessant cry was present in 7 patients (14\%). Priapism was noted in nearly 15 of male children. But Bawaskar et.al has noted occurrence of this clinical symptoms in as many as $10 \%$ of patients and this is similar to study done by balasubramaniam et al. ${ }^{12,13}$

In this study, $22 \%$ of patients had received the prazosin within 24 hours and $40 \%$ of patients received prazosin within $1-2 \mathrm{hrs}, 22 \%$ of patients received prazosin within $2-3 \mathrm{hrs}, 14 \%$ of patients received after $3-4 \mathrm{hrs}, 2 \%$ of patients after 4 hrs.
Complication were noted less frequently in children who received a dose a prazosin early ( $<3$ hrs of sting). By comparing other studies related to this in India, shows that early and effective administration of prazosin significantly reduced the incidence of complication. some patients were diagnosed already known case of cardiac disorders such as myocarditis, circulatory failure.

In this study $20 \%$ of patients received single dose of prazosin, $30 \%$ of patients received 2 doses of prazosin, $18 \%$ of patients received 3 doses of prazosin and $32 \%$ of patients received over 4 doses as per AIIMS protocol. The mean duration of hospital stay is 3 days. There was no mortality due to scorpion envenomation seen in period of study.

In this study 48 patient received the first aid management such as tetanus toxoid, paracetamol, diclofenac (given for the pain at the sting site), prazosin, dobutamine, pheniramine maleate, lignocaine, dopamine from local clinic, community health centre and primary healthcare centre for first aid, pain management and supportive care.

During hospitalisation all the 50 patients had received the IV fluids and prazosin at an average dose of $0.5 \mathrm{mg}, 34$ patients received the paracetamol and 15 patients received dobutamine. Majority of the children developed severe manifestation of scorpion envenomation, hence monitoring closely is needed. IV fluids and prazosin must be given as emergency measure. Most of the patients with myocardial dysfunction during scorpion sting study respond to dobutamine insertion. The study findings show early and effective use of prazosin showed good outcome through the time of sting and dose of prazosin given less time period indicates the better outcome.

\section{CONCLUSION}

The study finding shows that Early and effective use of prazosin treatment showed good outcome in patients. Less complications were seen in patients who received the first aid before hospitalization. This study concludes that majority of patient were exposed to complication due to shortfall of education, awareness and pre-hospitalization (first aid). We, as a clinical pharmacist, tried to create awareness and provide education to health care workers in all primary health care Centre through distributing pamphlets to general public in and around hospital.

\section{ACKNOWLEDGEMENTS}

We express our profound and sincere gratitude to our institutional guide Dr. V. P. Maheshkumar, Assistant professor, department of pharmacy, and Dr. R. Ramamoorthy, senior resident in paediatrics, RMMCH, Annamalai University, Annamalai Nagar, for their valuable guidance and support, constant inspiration, kind co-operation and great intend to us to fulfil our work in a successful manner. We express our gratitude to Dr. G. P Mohanta, professor, department of pharmacy for 
his constant encouragement, support and valuable suggestions throughout the duration of our project work. We shall be falling in our responsibility if we do not thank our friends for all the greatest help during our project work and also throughout our course. We thank all the patients who gave their consent and participated in the study, without whom the study would be nothing.

Funding: No funding sources

Conflict of interest: None declared

Ethical approval: The study was approved by the human ethics committee.

\section{REFERENCES}

1. Ganesh JS, Kumaravel A. study on the clinical profile of scorpion envenomation in childrens. Int $\mathrm{J}$ Contemp Pediatr. 2016;3:125-8.

2. Bawaskar HS, Bawaskar PH. Prazosin therapy and scorpion envenomation. J Assoc Physici Ind. 2000;48(12):1175-80.

3. Arivoli K, Ganesh J. A Study on the Clinical Profile of Scorpion Envenomation in Children. J Evolu Med Den Sci. 2015;4(90):15522-6.

4. Bawaskar HS, Bawaskar PH. Clinical profile of severe scorpion envenomation in children at rural setting. Ind Pedia. 2003;40(11):1072.

5. Bawaskar HS, Bawaskar PH. Prazosin in management of cardiovascular manifestations of scorpion sting. Lan. 1986;1(8479):510-1.

6. Pol R, Vanaki R, Pol M. The clinical profile and the efficacy of prazosin in scorpion sting envenomation in children of north Karnataka (India). J Clin Diagn Res. 2011;5(3):456-8.

7. Bhandari UK, Tripathi A, Sharma S, Pandey R. Scorpion sting envenomation presenting with Pulmonary edema in adults: A report of seven cases from Nepal. Ind J Med Sci. 2006;60:19-23.

8. Bawaskar HS, Bawaskar PH. Clinical profile of severe scorpion envenomation in children at rural setting. Ind Pedia. 2003;40(11):1072.

9. Abroug F, ElAtrous S, Nouira S, Haguiga H, Touzi N, Bouchoucha S. Serotherapy in Scorpion envenomation: a randomized controlled trial. Lanc 1999;354:906-9.

10. Soren C, Rao KN. Clinical profile scorpion sting envenomation in children. Int $\mathbf{J}$ Contemp Pediatr. 2016;3:865-7.

11. Fet V. Notes on the taxonomy of some old-world scorpions (Scorpiones: Buthidae, Chactidae, Ischnuridae, Scorpionidae). J Arachno. 1997;25(3):245-50.

12. Amaral CFS, Rezende NAD, Friere-Mara L. Acute Pulmonary Edema after TityusSerrulatus scorpion sting in children. Am J Cardiol. 1992;71:242-5.

13. Mahadevan S. Scorpion sting. Ind Pediatric J. 2000;37:504-14.

Cite this article as: Umapathi $\mathrm{K}$, Boopalan $\mathrm{P}$, Maheshkumar VP, Ramamoorthy R. A study on clinical profile, management and outcome in pediatric patients admitted with scorpion envenoma tion. Int J Basic Clin Pharmacol 2020;9:1560-4. 